\title{
Decoration of Silver Nanoparticles on Multiwalled Carbon Nanotubes: Antibacterial Mechanism and Ultrastructural Analysis
}

\author{
Ngo Xuan Dinh,, ${ }^{1,2}$ Nguyen Van Quy, ${ }^{3}$ Tran Quang Huy, ${ }^{4}$ and Anh-Tuan Le ${ }^{2}$ \\ ${ }^{1}$ University of Transport Technology, Hanoi 10000, Vietnam \\ ${ }^{2}$ Department of Nanoscience and Nanotechnology, Advanced Institute for Science and Technology (AIST), \\ Hanoi University of Science and Technology (HUST), No. 1, Dai Co Viet Street, Hai Ba Trung District, Hanoi 10000, Vietnam \\ ${ }^{3}$ International Training Institute for Materials Science (ITIMS), Hanoi University of Science and Technology, Hanoi 10000, Vietnam \\ ${ }^{4}$ National Institute of Hygiene and Epidemiology (NIHE), No. 1, Yecxanh Street, Hai Ba Trung District, Hanoi 10000, Vietnam
}

Correspondence should be addressed to Anh-Tuan Le; tuan.leanh1@hust.edu.vn

Received 9 December 2014; Revised 6 February 2015; Accepted 10 February 2015

Academic Editor: Yuan Chen

Copyright (c) 2015 Ngo Xuan Dinh et al. This is an open access article distributed under the Creative Commons Attribution License, which permits unrestricted use, distribution, and reproduction in any medium, provided the original work is properly cited.

Recently, development of carbon nanocomposites composed of carbon nanostructures and metal nanoparticles has attracted much interests because of their large potential for technological applications such as catalyst, sensor, biomedicine, and disinfection. In this work, we established a simple chemistry method to synthesize multiwalled carbon nanotubes (MWCNTs) decorated with silver nanoparticles (Ag-NPs) using a modified photochemical reaction (Tollens process). The formation and interaction of Ag-NPs with functionalized groups on the surface of MWCNTs were analyzed by X-ray diffraction, transmission electron microscopy, Raman spectroscopy, and Fourier-transform infrared spectroscopy. The average size of Ag-NPs on the MWCNTs was approximately $\sim 7 \mathrm{~nm}$ with nearly uniform size distribution. Antibacterial effect of Ag-MWCNTs nanocomposites was evaluated against two pathogenic bacteria including Gram-negative Escherichia Coli and Gram-positive Staphylococcus aureus bacteria. Interaction and bactericidal mechanism of Ag-MWCNTs with tested bacteria was studied by adapting the electron microscopy. Analysis on ultrastructural changes of bacterial cells indicates that antibacterial action mechanism of Ag-MWCNTs is physical interaction with cell membrane, the large formation of cell-Ag-MWCNTs aggregates, and faster destructibility of cell membrane and disruption of membrane function, hence resulting in cells death.

\section{Introduction}

In recent years, serious threats on global health problems were reported from outbreaks of infectious diseases and increasing resistance of the microorganisms towards antibiotics [1]. To prevent infectious pathogens, disinfection solutions should be done properly to eliminate transmission of these pathogens from infected environmental areas to safety of community and human health. Nanoantimicrobials were proved as an effective solution for the prevention of pathogenic microorganisms [2]. Over the past decades, various nanosized antibacterial agents such as metal, carbon, and metal oxide nanoparticles have been studied for potential in effective treatment of pathogenic microorganisms [3-5].

Among existing nanoantimicrobials, silver nanoparticles (Ag-NPs) were recognized as a promising candidate to fight against pathogens $[6,7]$. The Ag-NPs were found to exhibit superior antibacterial activity and broad spectrum of antimicrobial activity against bacteria, fungi, and even viruses [8]. However, the Ag-NPs showed two major shortcomings for application in practice [9]: (i) particles size instability of silver nanoparticles in aqueous solution leads to aggregation of particles and results in reduction in antibacterial activity 
of materials and (ii) when the using high concentrations, the Ag-NPs could exhibit a highly toxic potential to human cells and ecology. It was shown that main reason of Ag-NPsmediated cytotoxicity was mainly ascribed to the induction of reactive oxygen species (ROS) due to release of silver ions [8]. Therefore, findings of novel nanostructures as alternatives were proposed by decorating Ag-NPs on supporting materials to improve antibacterial performance of materials and minimize adverse effects of silver. Recently, development of carbon-silver nanocomposites composed of carbon nanostructures decorated with silver nanoparticles demonstrates a promising approach for various technological applications such as catalyst, sensor, biomedicine, and disinfection $[10,11]$.

Carbon nanotubes (CNTs) including single-walled CNTs (SWCNTs) and multiwalled CNTs (MWCNTs) have attracted great attentions as a supporting material because of their excellent properties such as high surface area and chemical stability [11]. Especially, with the larger surface area of MWCNTs, they can be used as effective templates to deposit the AgNPs on the surface of MWCNTs with high stability and outstanding antimicrobial activity [12]. Some previous reports indicated that the Ag-MWCNTs nanocomposites exhibited enhanced antibacterial activities and lower cytotoxicity as compared to alone Ag-NPs [12-15]. The Ag-NPs-decorated MWCNTs materials were found to show noticeable inhibition effect with different Gram-negative bacteria (Escherichia coli and Pseudomonas aeruginosa) and Gram-positive bacteria strains (Staphylococcus aureus). Additionally, Castle et al. in 2011 [13] revealed that the strong adhesion of nanoparticles on functionalized MWCNTs makes the Ag-NPs less toxic because they are not released easily to the cells. More recently, Seo et al. in 2014 [15] produced MWCNTs decorated with Ag-NPs with the use of ethanol as reducing agent. They also confirmed that $30 \mu \mathrm{g} / \mathrm{mL}$ of synthesized Ag-MWCNTs yielded an efficient level of antibacterial activity against Methylobacterium spp. and Sphingomonas spp. with negligible cytotoxicity toward both human and animal cells [15].

Several attempts have been made for enhancing the antibacterial activity and cellular function and excluding toxicology of composite materials by combining the Ag-NPs and MWCNTs [10-15]. In a recent work [16], we also noted that the strong binding of silver nanoparticles with functional groups on the surface of carbon nanomaterials made them attractive with stronger bactericidal behavior and lesser toxic than that of pure silver nanoparticles due to low release to the cells. However, a full understanding of the exact action mechanism of Ag-MWCNTs nanocomposites with microorganisms has not been fulfilled. Therefore, further studies at ultrastructural level to further understand the interaction and bactericidal mechanism of carbon-silver nanocomposites are really needed.

In this work, we present a simple method for decoration of Ag-NPs on the surface of MWCNTs by using a modified Tollens process. Antibacterial effects of prepared Ag-MWCNTs nanocomposites were evaluated against two pathogenic bacteria including Gram-negative Escherichia Coli and Grampositive Staphylococcus aureus bacteria. We provide more insights in interaction and bactericidal mechanism of these materials against tested bacteria in the light of ultrastructural studies.

\section{Experimental Procedures}

2.1. Chemicals. Silver nitrate $\left(\mathrm{AgNO}_{3}, 99.9 \%\right)$ and sodium hydroxide $(\mathrm{NaOH})$, ammonium hydroxide $\left(\mathrm{NH}_{3}, 25 \%\right)$, sulfuric acid $\left(\mathrm{H}_{2} \mathrm{SO}_{4}, 98 \%\right)$, nitric acid $\left(\mathrm{HNO}_{3}, 63 \%\right)$, oleic acid, and glucose that were used in this study were purchased from Shanghai Chemical Reagent.

The multiwalled carbon nanotubes (MWCNTs) (diameter $\sim 15-20 \mathrm{~nm}$; length $\sim 2.5 \mu \mathrm{m}$ ) were provided from Chungnam National University in Republic of Korea.

2.2. Synthesis of Silver Nanoparticles by Tollens Process. The silver nanoparticles were prepared by using a modified Tollens process as reported elsewhere $[17,18]$. Briefly, $1.7 \mathrm{~g}$ $(10 \mathrm{mmol})$ of $\mathrm{AgNO}_{3}$ was dissolved in $100 \mathrm{~mL}$ of deionized water. The $\mathrm{AgNO}_{3}$ solution was then precipitated with $0.62 \mathrm{~g}$ $(15.5 \mathrm{mmol})$ of sodium hydroxide (Aldrich, >99\%). The obtained precipitate, which is composed of $\mathrm{Ag}_{2} \mathrm{O}$, was filtered and dissolved in $100 \mathrm{~mL}$ of aqueous ammonia $(0.4 \% \mathrm{w} / \mathrm{w}$, $23 \mathrm{mmol}$ ) until a transparent solution of silver ammonium complex $\left[\mathrm{Ag}\left(\mathrm{NH}_{3}\right)_{2}\right]^{+}(\mathrm{aq})$ formed. Up to $2.5 \mathrm{~g}(8.9 \mathrm{mmol})$ of oleic acid was then added dropwise into the complex, and the resulting solution was gently stirred for $2 \mathrm{~h}$ at room temperature until the complete homogeneity of the reaction mixture was achieved. The reduction process of the silver complex solution by the addition of $2 \mathrm{~g}(11.1 \mathrm{mmol})$ of glucose was initiated with UV irradiation. A UV $\operatorname{lamp}(\lambda=365 \mathrm{~nm}, 35 \mathrm{~W})$ was used as a light source to stimulate the reduction process.

2.3. Acid Treatment of MWCNTs. First, $100 \mathrm{mg}$ of pristine MWCNTs (diameter $\sim 15-20 \mathrm{~nm}$; length $\sim 2.5 \mu \mathrm{m}$ ) was thermally oxidized at $450^{\circ} \mathrm{C}$ for $1 \mathrm{~h}$ to remove amorphous carbon in samples. Next, $50 \mathrm{mg}$ of the oxidized MWCNTs was treated in $100 \mathrm{~mL}$ of an acid mixture of $\mathrm{HNO}_{3}$ and $\mathrm{H}_{2} \mathrm{SO}_{4}$ $(1: 3 \mathrm{vol} / \mathrm{vol})$ at $90^{\circ} \mathrm{C}$ for $12 \mathrm{~h}$ to produce $\mathrm{OH}$ - and/or $\mathrm{COOH}$ functionalized MWCNTs. The samples were then filtered, washed with distilled water, and dried under vacuum at $120^{\circ} \mathrm{C}$ for $10 \mathrm{~h}$. Finally, $30 \mathrm{mg}$ of the $\mathrm{OH}$ - and/or $\mathrm{COOH}-$ functionalized MWCNTs was dispersed in $100 \mathrm{~mL}$ of deionized water for later analysis.

2.4. Decoration of Ag-NPs on Functionalized MWCNTs. Next, the decoration of Ag-NPs on the $\mathrm{OH}$ - and/or $\mathrm{COOH}$ functionalized MWCNTs was conducted. We used the same process for synthesis of Ag-NPs using Tollens process as mentioned in Section 2.2. After the formation of silver ammonium complex occurred, $30 \mathrm{~mL}$ of functionalized MWCNTs was added with the $\operatorname{Ag}\left[\left(\mathrm{NH}_{3}\right)_{2}\right]^{+}$silver ammonia complex and stirred for $30 \mathrm{~min}$. The reduction process to metallic $\mathrm{Ag}^{\circ}$ NPs was formed by the addition of glucose $(2 \mathrm{~g})$ as reducing agent and oleic acid (2.5 g) as stabilizing agent. The reduction reaction was also initiated with UV irradiation. The UV treatment was carried out for 10-12 h under vigorous stirring without additional heating. After $12 \mathrm{~h}$ irradiation, the Ag-NPs were decorated on surface of functionalized MWCNTs. The 
resulting solid products of Ag-MWCNTs nanocomposites were collected by centrifugation and were purified by washing with deionized water and dried under vacuum at $120^{\circ} \mathrm{C}$ for $8-$ $10 \mathrm{~h}$.

2.5. Characterization Techniques. Transmission electron microscopy (TEM, JEOL-JEM 1010) was conducted to investigate the morphology and size distribution of as-prepared MWCNTs, Ag-NPs, and Ag-MWCNTs nanocomposite. Also, high resolution TEM (Tecnai, G20, $200 \mathrm{kV}$, FEI) was used to determine the formation of Ag nanocrystals on MWCNTs. The samples for TEM/HRTEM characterization were prepared by placing a drop of colloidal solution on a carboncoated copper grid that was dried at room temperature. The composition of the Ag-MWCNTs nanocomposite was characterized by energy-dispersive X-ray (5410 LV JEOL). The crystalline structure of as-prepared samples was analyzed by X-ray diffraction (XRD, Bruker D5005) using $\mathrm{CuK} \alpha$ radiation $(\lambda=0.154 \mathrm{~nm})$ at a step of $0.02^{\circ}(2 \theta)$ at room temperature. The background was subtracted using linear interpolation method. The chemical groups of MWCNTs and Ag-MWCNTs were characterized using FTIR measurements, samples were collected with one layer coating in potassium bromide and compressed into pellets, and spectra in the range of $1000 \mathrm{~cm}^{-1}$ to $4000 \mathrm{~cm}^{-1}$ were recorded with Nicolet 6700 FT-IR instrument. The UV-vis absorbance spectra were recorded using a HP 8453 spectrophotometer, and the absorption spectrum of all suspension samples in $10 \mathrm{~mm}$ path length quartz cuvettes was $300 \mathrm{~nm}$ to $900 \mathrm{~nm}$. Raman measurement was conducted using $633 \mathrm{~nm}$ of He-Ne laser excitation. The content of silver present in bare silver samples and nanocomposites samples was determined using a method of atomic absorption spectroscopy (AAS, Shimadzu AA-6300).

\subsection{Evaluation of Antibacterial Activity}

2.6.1. Bacterial Strains and Culture Medium. Bacterial strains chosen for this study were Gram-negative Escherichia Coli (ATCC 43888) and Gram-positive Staphylococcus aureus (ATCC 43300). These strains were provided from the Department of Virology at the National Institute of Hygiene and Epidemiology (NIHE) in Hanoi.

The growth of cell cultures was executed in a LuriaBertani (LB) medium (1\% tryptone, $0.5 \%$ yeast extract, and $1 \% \mathrm{NaCl}, \mathrm{pH} 7$ ). Next, the culture medium containing bacteria was kept in an incubator for $24 \mathrm{~h}$ at the temperature $37^{\circ} \mathrm{C}$; then, the content of bacteria reached $\sim 10^{7}-10^{8} \mathrm{CFU} / \mathrm{mL}$, where the CFU is the colony forming unit.

2.6.2. Paper-Disc Diffusion Method. The paper-disc diffusion method was used to evaluate the antibacterial activity of the studied samples against two tested bacteria. Using the spread plate method, nutrient agar plates were inoculated with $100 \mu \mathrm{L}$ of bacterial suspension containing $10^{5} \mathrm{CFU}$. Sterile Whatman number 1 filter paper discs with a diameter of $5 \mathrm{~mm}$ were immersed in $10 \mathrm{~mL}$ of composites samples at different silver concentrations from $10 \mu \mathrm{g} / \mathrm{mL}, 20 \mu \mathrm{g} / \mathrm{mL}, 30 \mu \mathrm{g} / \mathrm{mL}$, and $50 \mu \mathrm{g} / \mathrm{mL}$ and then placed on the plates inoculated with
$100 \mu \mathrm{L}$ of inoculum containing $10^{7}-10^{8} \mathrm{CFU} / \mathrm{mL} /$ of cultured bacteria. It was noted that the concentration here was corrected for the content of silver in composite samples. A filter paper disc was loaded with only silver NPs solution for comparison purpose. Control plates were maintained with discs containing distilled water. These plates were incubated at $37^{\circ} \mathrm{C}$ for $24 \mathrm{~h}$ and the diameters of zone of inhibition (ZOI) around Ag-MWCNTs were measured by subtracting the disc diameter from the total inhibition zone diameter.

\subsection{Ultrathin Sectioning Sample Preparation of Bacterial Cells.} In order to obtain further understanding of the bactericidal and interaction mechanism of studied samples, ultrathin sectioning technique was carried out to observe the ultrastructural changes of bacterial cells destroyed by action of the MWCNTs, Ag-NPs, and Ag-MWCNTs nanocomposite. After 24-hour inoculation of bacteria in the nutrient broth, $1 \mathrm{~mL}$ Ag-MWCNTs was added to a tube. The tube was agitated and placed in a water bath at $20^{\circ} \mathrm{C}$ for 1 hour. After that, $2 \mathrm{~mL}$ mixed solution was collected and centrifuged at $2500 \mathrm{rpm}$ around $5 \mathrm{~min}$. The pellet was collected and resuspended and fixed in $2.5 \%$ glutaraldehyde in $0.1 \mathrm{M}$ cacodylate buffer $\mathrm{pH}$ 7.2 and kept overnight at $4^{\circ} \mathrm{C}$. The sample was then rinsed carefully several times in $0.1 \mathrm{M}$ cacodylate buffer $\mathrm{pH} 7.2$; the final pellet was fixed with $1 \%$ OsO4 in the same buffer for $60 \mathrm{~min}$ and subsequently dehydrated in graded ethanol (50$100 \%$ ), washed in propylene oxide, and infiltrated for $6 \mathrm{~h}$ in a 1:1 mixture of propylene oxide and epoxidic resin (Epon). The samples were finally embedded in Epon 812. Ultrathin $70 \mathrm{~nm}$ thick sections were obtained with an ultramicrotome (Ultracut UC6, Leica) and stained with uranyl acetate and lead citrate. The polymerized samples were sectioned into ultrathin slices $60-90 \mathrm{~nm}$ in thickness and placed on the carbon-coated copper grids (300 meshes). The analyses of ultrastructural changes of interior of the bacteria cells were conducted by transmission electron microscopy (TEM, JEM 1010, JEOL).

\section{Results}

3.1. Formation of Ag-NPs on Functionalized MWCNTs. A two-step process for synthesis of Ag-MWCNTs nanocomposite was shown in Figure 1. Our previous reports [17, 18] showed that the Tollens process enables us to produce silver colloids with small sizes and stable aqueous dispersions at high yield $\sim 99 \%$. In our present work, we employed this process to decorate silver NPs on the surface of MWCNTs with yield $\sim 98 \%$. In a two-step process, the first step of the acid treatment of MWCNTs is to create oxygen-containing functional groups (e.g., $\mathrm{OH}, \mathrm{COOH}$ ) on the surface of MWCNTs. These functionalized groups make the MWCNTs well dispersed in aqueous medium with high stability. The purpose of surface modification of MWCNTs is to introduce more binding sites for anchoring the precursors of silver ions or silver NPs. In second step, the silver NPs were formed on the functional groups of MWCNTs via reduction of silver ions by glucose with assistance of UV irradiation in Tollens reaction. 


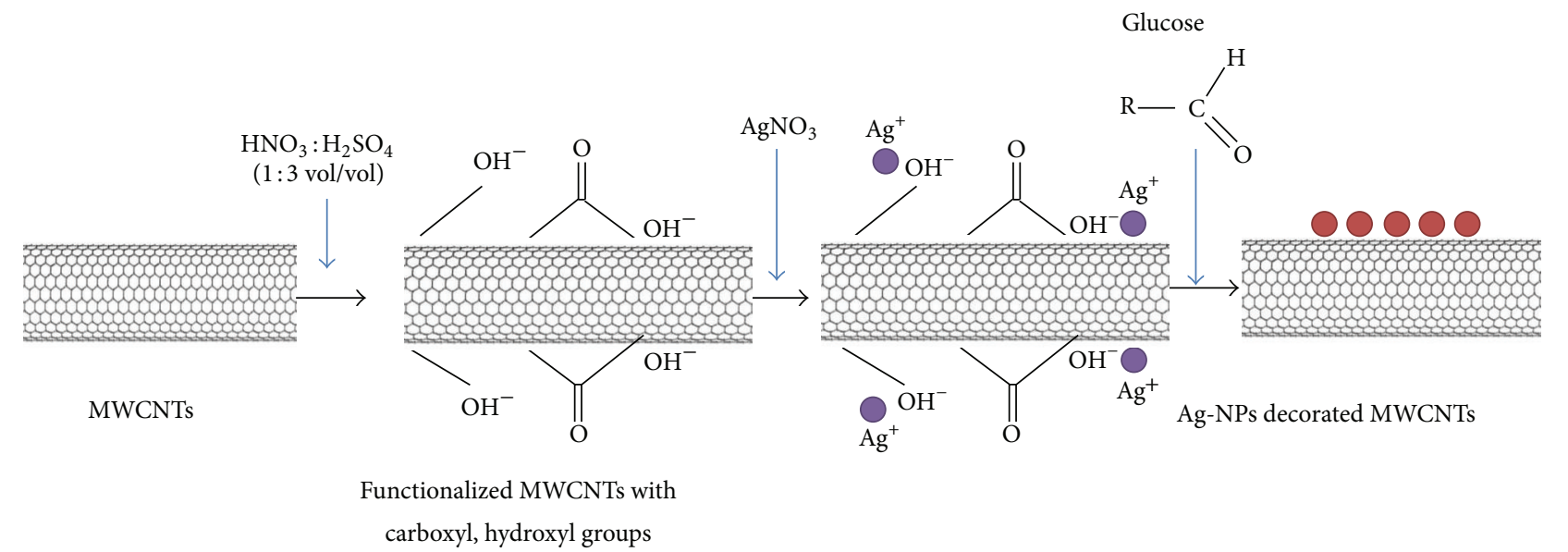

$\mathrm{Ag}\left(\mathrm{NH}_{3}\right)_{2}^{+}$

Ag-NPs

FIgURE 1: Two-step protocol for decoration of silver nanoparticles on the multiwalled carbon nanotubes.

The formation of Ag-NPs on the surface of MWCNTS was confirmed using TEM and XRD measurements. Figures 2(a) and 2(b) display the TEM images of functionalized MWCNTs and Ag-MWCNTs. It can be seen from Figure 2(a) that the diameters of the functionalized MWCNTs are about $25-30 \mathrm{~nm}$. After the photochemical reaction, it can be observed that a large number of silver nanoparticles were anchored to surface of carbon nanotubes as shown in Figure 2(b). The TEM observations also reveal that the adhered nanoparticles have quasi-spherical morphologies and are finely dispersed on the functionalized CNTs [16]. To compare the particle size, we also measured TEM image of silver nanoparticles. The inset of Figure 2(b) showed uniform distribution of prepared Ag-NPs alone (without addition of MWCNTs); the average particle sizes of Ag-NPs calculated from TEM image obtained about $\sim 5 \mathrm{~nm}$. In contrast, the average particle sizes of Ag-NPs decorated on MWCNTs are about $\sim 7-8 \mathrm{~nm}$. Almost there is no aggregation of Ag-NPs on the surface of MWCNTs. High-resolution transmission electron microscopy (HRTEM) along with EDS analysis was employed to confirm the existence of Ag nanocrystals on the MWCNTs. Figures 2(c) and 2(d) show the bright-field TEM image along with its EDS spectrum of Ag nanocrystals decorated on the MWCNTs. The EDS spectrum (Figure 2(d)) reveals the existence of Ag element. HRTEM analysis confirmed the Ag nanocrystals decorated on the MWCNTs.

Additionally, the structure of samples was further confirmed by using XRD analysis. The XRD patterns of AgNPs, MWCNTs, and Ag-MWCNTs samples were displayed in Figure 2(e). It can be seen that the pristine MWCNTs sample exhibits a strong (002) peak at $26.2^{\circ},(100)$ peak at $44.8^{\circ}$, and (004) peak at 54.3 (JCPDS No. 01-0646). After the decoration of silver nanoparticles, the XRD pattern of Ag-MWCNTs shows three distinct diffraction peaks at 2 theta $=38.2^{\circ}, 44.4^{\circ}$, and $64.5^{\circ}$, which correspond to the (111), (200), and (220) crystalline planes of metallic Ag (JCPDS No. 04-0783). Our calculation from the XRD patterns according to Scherrer expression indicates the average particles sizes of Ag-NPs ( $\sim 6 \mathrm{~nm})$ and Ag-MWCNTs $(\sim 8 \mathrm{~nm})$. This result is fully consistent with the calculation from TEM images. Furthermore, the broadening of the full width at half maximum (FWHM) of the XRD pattern reveals the nanoscale sizes of Ag-NPs [19]. The obtained TEM and XRD results confirmed that the Ag-NPs are successfully anchored to the surface of functionalized MWCNTs using a modified photochemical method (Tollens process) [19]. A representative picture of prepared samples including the Ag-NPs, functionalized MWCNTs, and Ag-MWCNTs was shown in Figure 2(f). The color of colloidal solutions changes from yellow to brown one depending on the concentration of silver; for example, the color of solution changes from yellow (silver concentration $<500 \mathrm{ppm}$ ) to brown (large silver concentration $\sim 1000 \mathrm{ppm}$ ) (see Figure 2(f)).

3.2. Interaction of Ag-NPs on Surface of MWCNTs. To elucidate the interaction of Ag-NPs with functional groups on the surface of MWCNTs, FTIR and Raman analyses were conducted. Figure 3(a) shows the FTIR spectra of MWCNTs and Ag-MWCNTs samples. It can be seen that, with pristine MWCNTs, the presence of adsorption bands at $3447 \mathrm{~cm}^{-1}$ corresponds to the $-\mathrm{OH}$ stretching vibration. The $\mathrm{C}=\mathrm{C}$ bonding of aromatic rings of the carbon skeleton structure were found at $1624 \mathrm{~cm}^{-1}$, and $\mathrm{O}-\mathrm{H}$ deformations of the $\mathrm{COOH}$ groups were observed at $1383 \mathrm{~cm}^{-1}$ [16]. This obtained FTIR result confirms that the addition of functional carboxyl and hydroxyl groups on the surface of MWCNTs was successfully done through an aggressive oxidation treatment with a $\mathrm{HNO}_{3} / \mathrm{H}_{2} \mathrm{SO}_{4}$ mixture. However, a noticeable change in the intensity of the adsorption bands of the oxygenated functional groups was found for that of AgMWCNTs nanocomposite. This finding results mainly from both presence of the Ag-NPs on the surface of MWCNTs and a slight reduction of MWCNTs by glucose during the synthesis process of Ag-MWCNTs [16]. The change of O-H stretch 


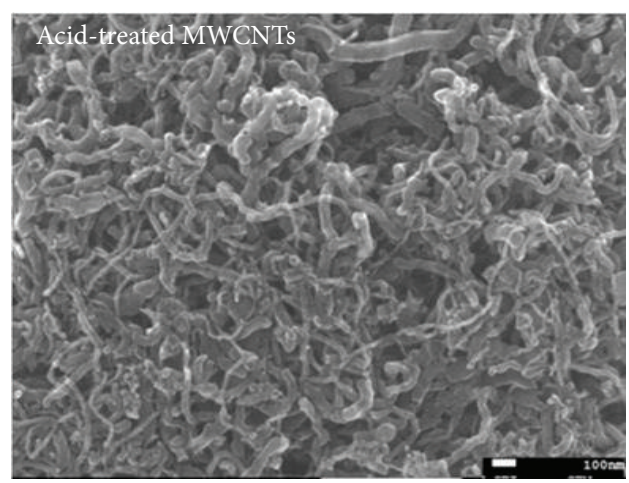

(a)

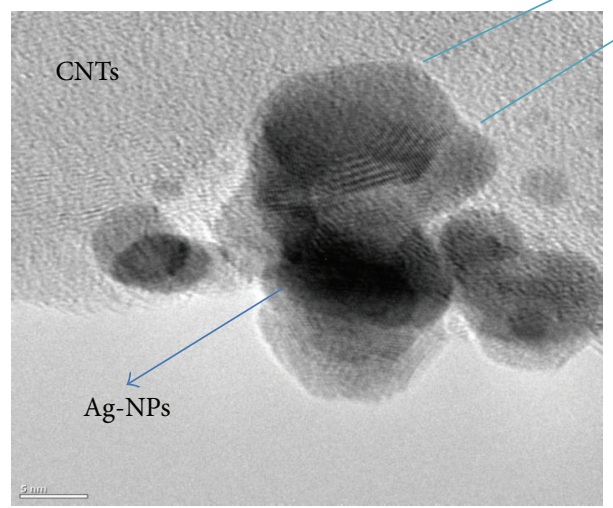

(c)

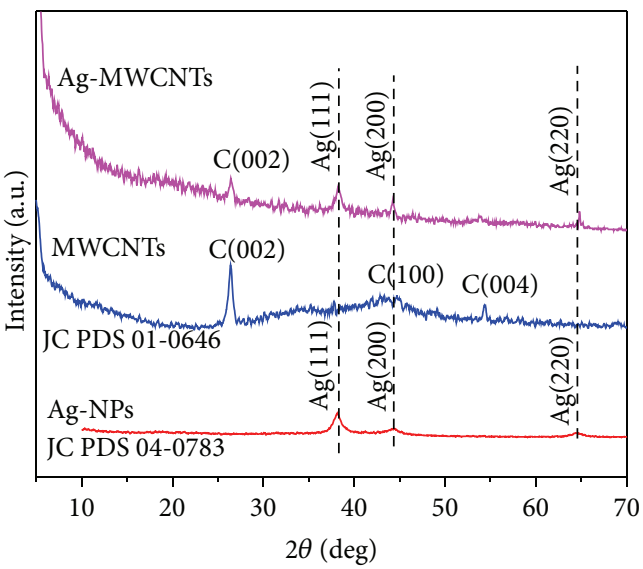

(e)

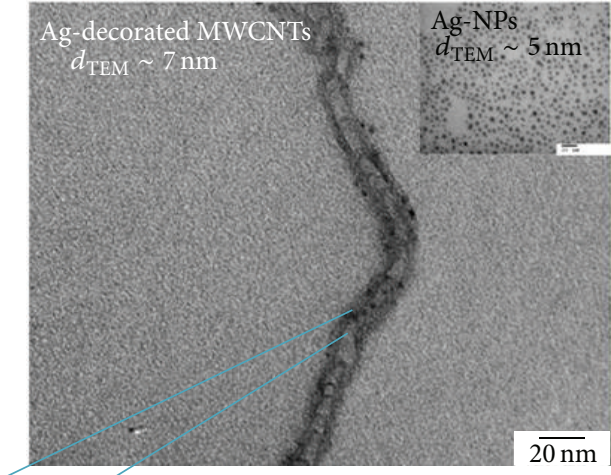

(b)

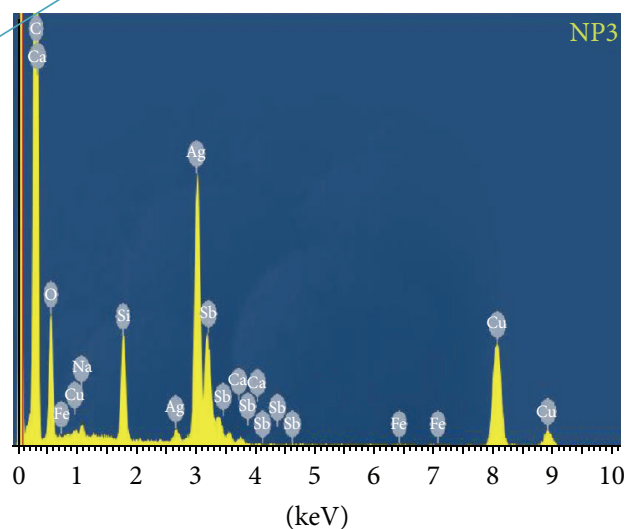

Full scale 2698 cts cursor: -0.008 (3916 cts)

(d)

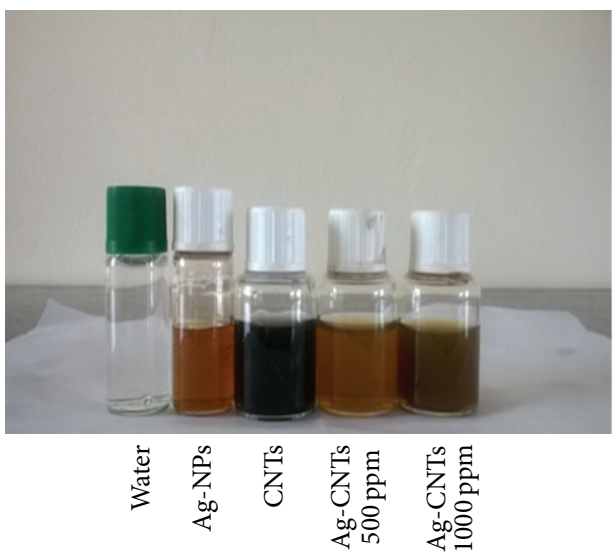

(f)

FIGURE 2: TEM images of (a) acid-treated MWCNTs and (b) Ag-MWCNTs nanocomposite; the inset of (b) shows a TEM image of prepared silver nanoparticles; (c) HRTEM image of Ag nanocrystals on MWCNTs; (d) EDS analysis of Ag-MWCNTs; (e) XRD patterns of Ag-NPs, MWCNTs, and Ag-MWCNTs samples; and (f) colloidal solutions of studied samples after synthesis process.

absorption intensity in the composite sample is attributed to interactions between silver ions and hydroxyl group of MWCNTs [20]. The variation of the other peaks $(1600,1400$, and $1063 \mathrm{~cm}^{-1}$ ) in the case of Ag-MWCNTs demonstrates the interaction between silver ions and functional groups through the formation of a coordination bond or through simple electrostatic attraction. The FTIR results demonstrate that strong interactions may exist between $\mathrm{Ag}$-NPs and the remaining hydroxyl and carboxyl groups on the surface of the MWCNTs [16, 19].

Raman spectroscopy was used to investigate the crystallinity and the structural changes of carbon framework of MWCNTs. As one can see from Figure 3(b), the MWCNTs sample shows prominent peaks at $1326 \mathrm{~cm}^{-1}$ (D band) and at $1572 \mathrm{~cm}^{-1}$ (G band), and corresponding peaks for AgMWCNTs sample are observed at $1315 \mathrm{~cm}^{-1}$ and $1592 \mathrm{~cm}^{-1}$. 


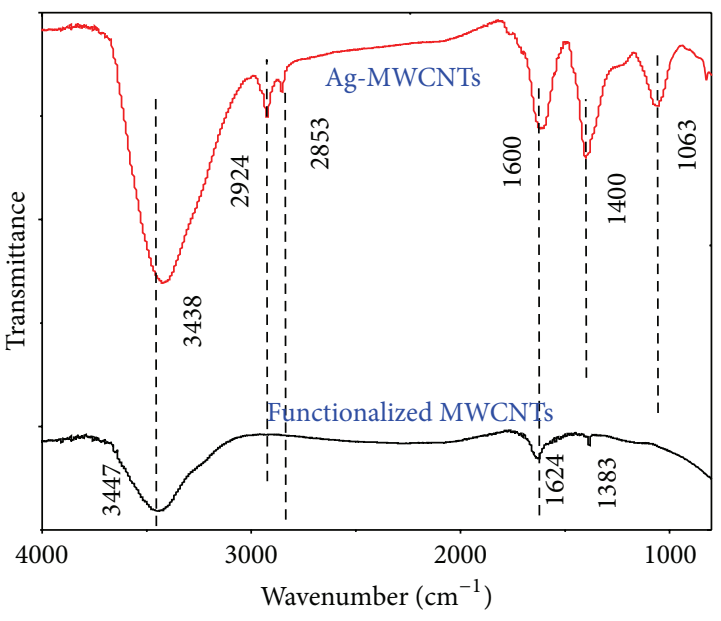

(a)

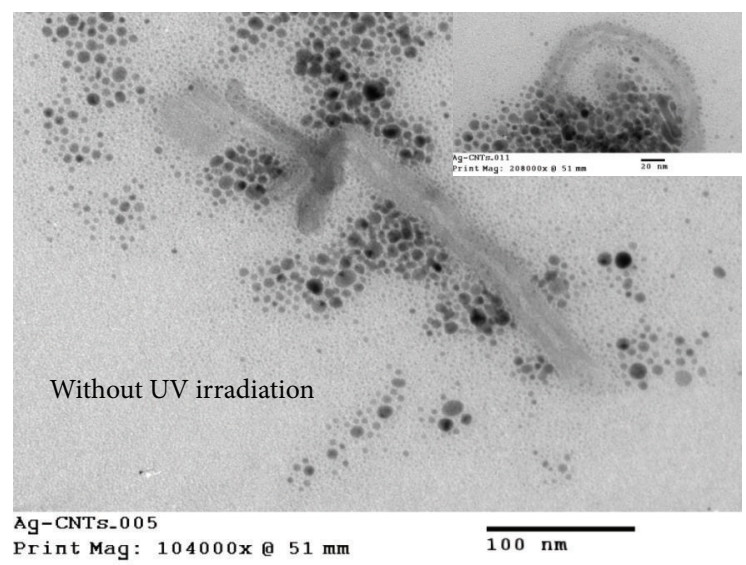

(c)

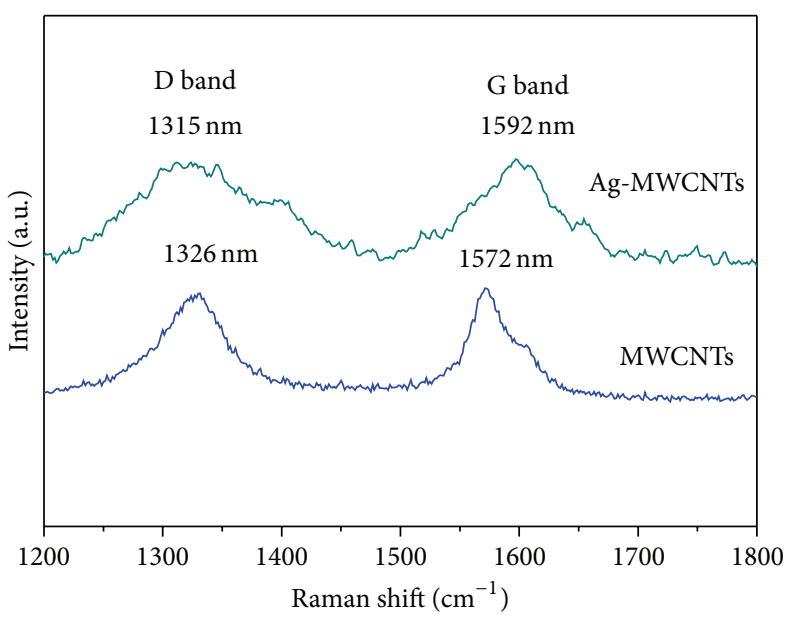

(b)

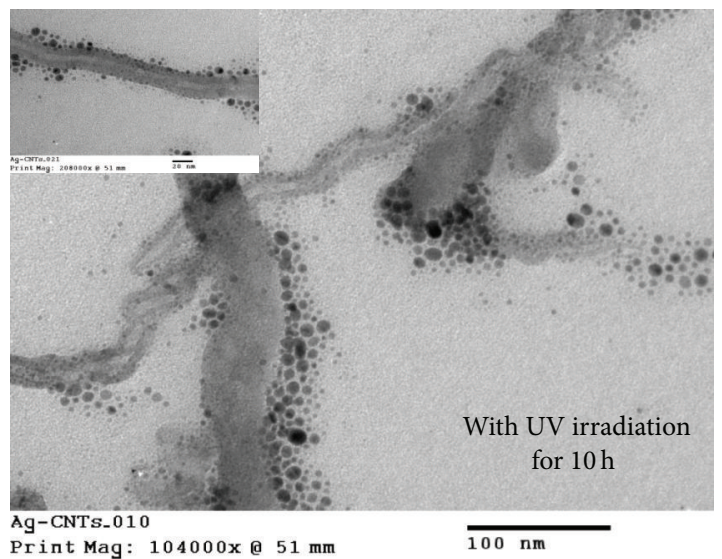

(d)

Figure 3: (a) FTIR spectroscopy and (b) Raman spectroscopy of MWCNTs and Ag-MWCNTs. (c, d) TEM images of Ag-MWCNTs without and with use of UV irradiation.

The $\mathrm{D}$ band represents edges, other defects, and disordered carbon due to vibration of $\mathrm{sp}^{3}$-bonded carbon atoms and impurities, whereas the $\mathrm{G}$ band arises from the zone center $\mathrm{E}_{2 \mathrm{~g}}$ mode, assigning to the ordered $\mathrm{sp}^{2}$-bonded $\mathrm{C}$ atoms $[21,22]$. A significant frequency shift toward a smaller wavenumber of the D-band is found in Ag-MWCNTs (about $34 \mathrm{~cm}^{-1}$ ) in comparison with pristine MWCNTs. This result shows a higher level of disorder of the graphene layers and increased numbers of defects because of the partial reduction of MWCNTs by glucose during the synthesis of the AgMWCNTs [16]. The Raman analysis showed that the carbon framework of MWCNTs was modified by the formation of Ag-NPs.

Besides, the ratio of intensity of the $\mathrm{D}$ band to that of the $\mathrm{G}$ band $\left(I_{\mathrm{D}} / I_{\mathrm{G}}\right)$ is also increased upon the adsorption of Ag-NPs. The ratio value of $I_{\mathrm{D}} / I_{\mathrm{G}}$ represents the degree of disorder and the average size of the $\mathrm{sp}^{2}$ domains $[22,23]$. The intensity ratio of $I_{\mathrm{D}} / I_{\mathrm{G}}$ has a linear relation to the inverse of the in-plane crystallite dimension. The $I_{\mathrm{D}} / I_{\mathrm{G}}$ values were approximately 0.99 and 1.01 for MWCNTs and Ag-MWCNTs samples, respectively. The observed increasing $I_{\mathrm{D}} / I_{\mathrm{G}}$-value suggested a decrease in in-plane size of graphene upon the reduction process [19]. The partial reduction of MWCNTs could cause fragmentation along the reactive sites and might yield new graphitic domains, leading to smaller sizes and higher number of graphene than that of MWCNTs before the reduction. In the present study, the higher increased $I_{\mathrm{D}} / I_{\mathrm{G}^{-}}$ value of the Ag-MWCNTs than that of the MWCNTs is likely attributed to the surface-enhanced Raman scattering from the intense local electromagnetic fields of Ag-NPs that accompanies plasmon resonance effect [16].

The previous studies revealed that the MWCNTs without surface modification would lead to poor dispersion and formed large particles sizes because of insufficient binding sites for anchoring silver nanoparticles [23]. Therefore, the surface functionalization of CNTs is necessary important step to increase the surface binding sites, avoid the aggregation of silver NPs, improve the dispersions, and reduce the particles sizes of nanoparticles. Indeed, the functional groups on the surface of MWCNTs would produce the nucleation sites for deposition and dispersions of silver nanoparticles on the surface of CNTs. The linkage of prepared silver nanoparticles 
TABLE 1: Summary of zone of inhibition for studied samples against E. coli and S. aureus bacteria.

\begin{tabular}{|c|c|c|c|c|c|c|}
\hline Antibacterial evaluation & $\begin{array}{l}\text { MWCNTs } \\
30 \mu \mathrm{g} / \mathrm{mL}\end{array}$ & $\begin{array}{c}\text { AgNPs } \\
30 \mu \mathrm{g} / \mathrm{mL}\end{array}$ & $\begin{array}{c}\text { Agl-MWCNTs } \\
10 \mu \mathrm{g} / \mathrm{mL}\end{array}$ & $\begin{array}{c}\text { Ag2-MWCNTs } \\
20 \mu \mathrm{g} / \mathrm{mL} \\
\end{array}$ & $\begin{array}{c}\text { Ag3-MWCNTs } \\
30 \mu \mathrm{g} / \mathrm{mL}\end{array}$ & $\begin{array}{c}\text { Ag4-MWCNTs } \\
50 \mu \mathrm{g} / \mathrm{mL}\end{array}$ \\
\hline $\begin{array}{l}\text { Inhibition zone }{ }^{\mathrm{a}} \\
\text { (E. coli) }\end{array}$ & - & 1.3 & 0.6 & 1.3 & 1.7 & 2.2 \\
\hline $\begin{array}{l}\text { Inhibition zone }{ }^{\mathrm{a}} \\
\text { (S. aureus) }\end{array}$ & - & 1.1 & 0.5 & 1.4 & 1.5 & 1.9 \\
\hline
\end{tabular}

${ }^{\mathrm{a}}$ Measured from paper-disk diffusion method ( $\left.\mathrm{mm}\right)$.

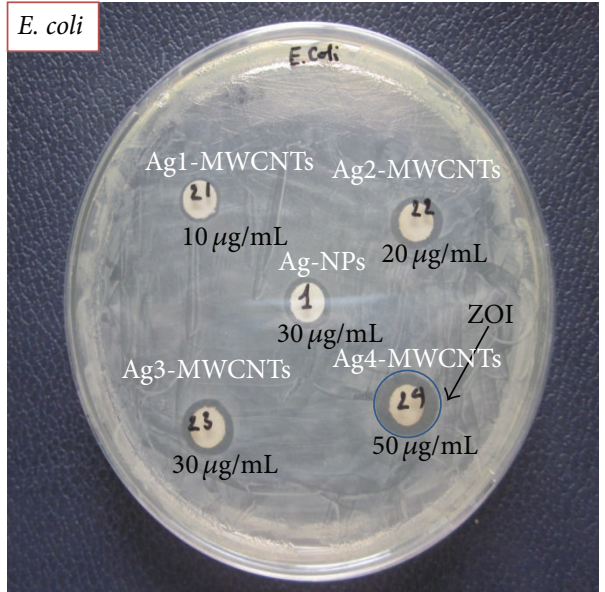

(a)

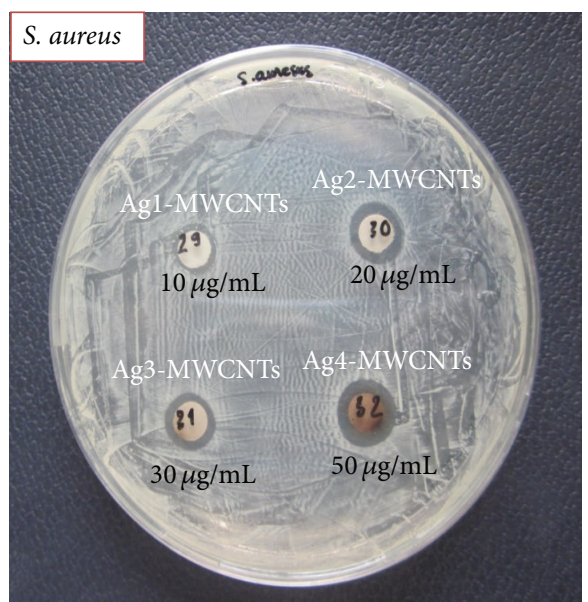

(b)

FIgURE 4: Antibacterial activity of Ag-MWCNTs samples against E. coli and S. aureus bacteria.

with functional groups on the surface of MWCNTs was confirmed from FTIR and Raman measurements.

The use of Tollens process with UV irradiation enables us to produce small particles size of silver NPs and high aqueous dispersions $[24,25]$. The UV irradiation plays a main role in achieving high dispersions of silver nanoparticles on the surface of MWCNTs and their size distribution [16, 19]. In order to prove this statement, we measured TEM images of Ag-MWCNTs nanocomposite with and without use of UV irradiation for comparison. As shown in Figure 3(c), without UV irradiation the aggregation of silver nanoparticles and poor dispersions of silver NPs on the surface of CNTs was found. However, when using UV irradiation, the silver NPs were finely formed on the surface of CNTs and almost no aggregation of silver nanoparticles was observed.

3.3. Antibacterial Activity Analysis. The antibacterial activities of Ag-NPs, MWCNTs, and Ag-MWCNTs nanocomposite were initially assessed with the paper-disc diffusion method, which is widely used for quick antibiotic susceptibility determinations [16]. Figures 4(a) and 4(b) show the photographs of result of antibacterial test for studied samples using paperdisc diffusion method against Gram-negative E. coli and Gram-positive $S$. aureus bacteria. The antibacterial effects of Ag-MWCNTs samples at different silver concentrations are from $10 \mu \mathrm{g} / \mathrm{mL}, 20 \mu \mathrm{g} / \mathrm{mL}, 30 \mu \mathrm{g} / \mathrm{mL}$, and $50 \mu \mathrm{g} / \mathrm{mL}$. The antibacterial ability of pure Ag-NPs sample $(30 \mu \mathrm{g} / \mathrm{mL})$ was also tested for comparison purpose.
It can be seen that both Ag-NPs and Ag-MWCNTs composite samples were found to exhibit significant inhibitory effect against both $E$. coli and $S$. aureus bacteria. The diameter of zone of inhibition (ZOI) for studied samples was measured and summarized in Table 1 . The obtained results reveal that the Ag-MWCNTs show the larger inhibition zone than that of pure Ag-NPs and pristine MWCNTs indicating the higher antibacterial activity of the composite material [16]. This finding suggests that the bacterial growth inhibition of the composite sample might be synergetic effect resulting from both the Ag nanoparticles and MWCNTs. The existence of zone of inhibition suggests that the Ag-MWCNTs can kill the bacteria by direct contact through disruption of bacterial membrane function. It is also emphasized that the antibacterial activity of as-prepared Ag-NPs and AgMWCNTs samples was more effective against $E$. coli bacteria than that of $S$. aureus bacteria. This may be from the thinner thickness of the peptidoglycan layer of Gram-negative E. coli bacteria as compared to that of the Gram-positive $S$. aureus bacteria [16-18].

3.4. Ultrastructural Analysis on Interaction of Ag-MWCNTs with E. coli and S. aureus Bacterial Cells. To provide more rudimentary insights into the interaction and bactericidal mechanism between the Ag-MWCNTs nanocomposites with tested bacteria, the ultrastructural analysis of bacterial cells when exposed to Ag-MWCNTs was conducted. The colloidal solutions of studied samples were dropped onto the surface 

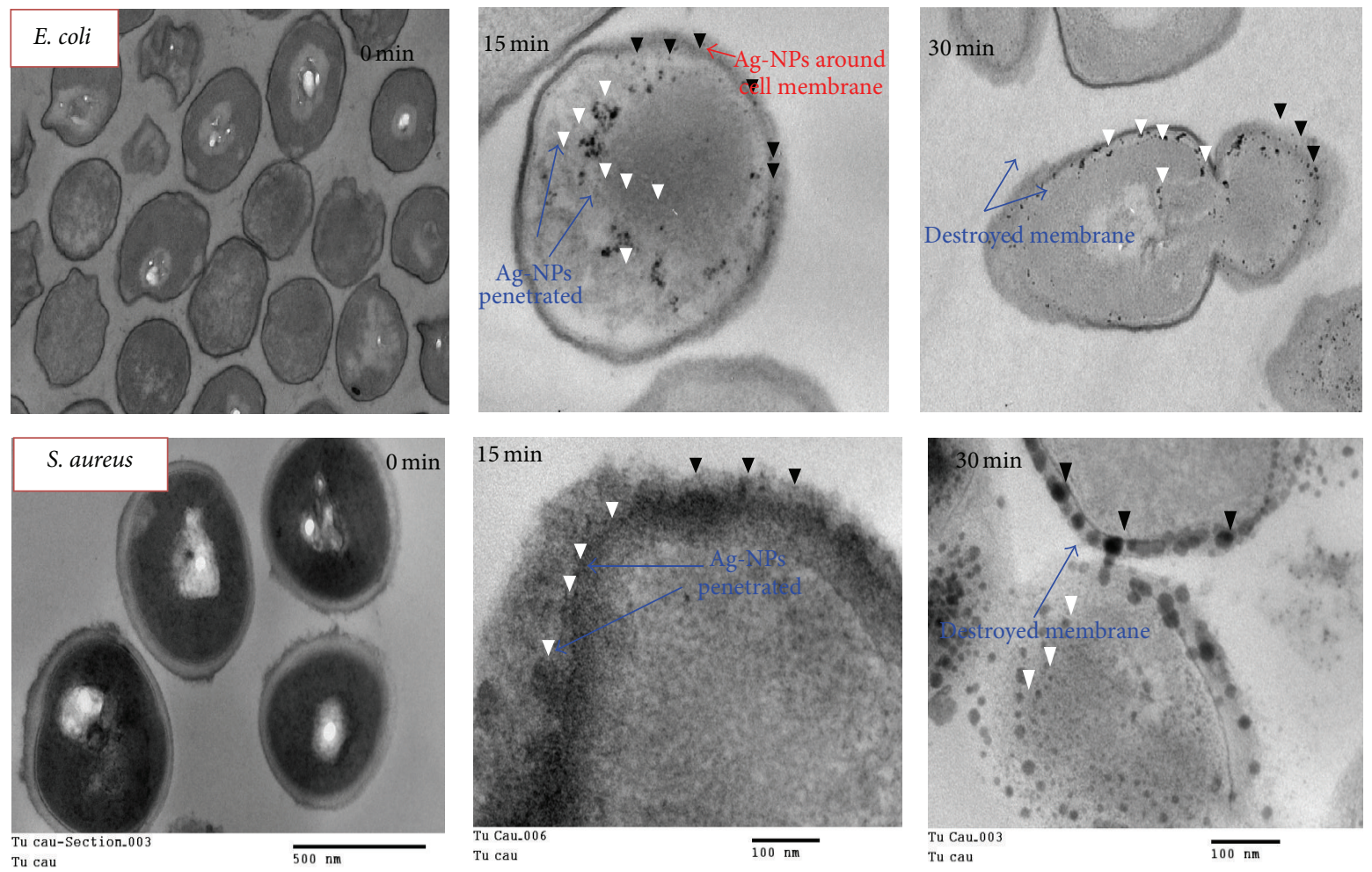

FIGURE 5: The cross-sectional TEM images showing different stages of interaction of Ag-NPs samples with E. coli and S. aureus bacteria cells after $0 \mathrm{~min}, 15 \mathrm{~min}$, and $30 \mathrm{~min}$.

of $E$. coli and S. aureus bacteria grown on agar plates. After $0 \mathrm{~min}, 15 \mathrm{~min}$, and $30 \mathrm{~min}$, slices of $E$. coli and $S$. aureus bacterial cells were taken out and underwent the sectioning method for TEM observation [16-18]. Figures 5 and 6 display the cross-sectional TEM images showing different stages of interaction of Ag-NPs sample (for comparison) and AgMWCNTs nanocomposites with E. coli and S. aureus bacteria cells after $0 \mathrm{~min}, 15 \mathrm{~min}$, and $30 \mathrm{~min}$, respectively.

First, for the case of pure Ag-NPs, it was established that the antibacterial mechanism of the Ag-NPs is a complex process [26], in which the silver NPs and their ions caused by the release of silver ions $\mathrm{Ag}^{+}$can produce free radicals, resulting in induction of oxidative stress (i.e., reactive oxygen species (ROS)) [27]. The produced ROS can irreversibly damage bacteria by multiple mechanisms (such as direct attachment to cell membrane and disruption of membrane integrity, changes in membrane permeability, interaction with proteins and disruption of their regular function, interference with DNA replication, and causing DNA damage), finally resulting in cell bacterial death $[26,27]$. As it can be seen in Figure 5, at different magnifications and sections, our microscopic analysis showed that some Ag-NPs bindings around both the E. coli and $S$. aureus cell membranes (black arrowhead) as well as inside the cells (white arrowhead) were found. The action mechanism of Ag-NPs can be understood as follows: the Ag-NPs first attached to the surface of the cell membrane and then penetrated further inside the bacteria. It should be noted that, however, only Ag-NPs with sufficiently small diameters could penetrate into the cells (usually $<10 \mathrm{~nm}$ ) [18].
With increasing interaction time, the Ag-NPs come further into bacteria cells and interact with other components such as DNA, proteins. As observed, after 30-minute interaction, the cytoplasm of the bacteria was completely destroyed as the Ag-NPs penetrated the cell (see Figure 5). This ultrastructural analysis probes how E. coli and $S$. aureus bacterial cells can be destroyed by the Ag-NPs $[16,18]$.

Second, for the case of pristine MWCNTs, it has been known that carbon-based nanoparticles were found to exhibit high antimicrobial activity [28]. Previous studies revealed that allotropic types of carbon such as fullerenes, carbon nanotubes (CNTs), and graphene oxide (GO) showed potent microcidal properties $[29,30]$. It was evidenced that the size of carbon nanotubes was an important factor affecting their antibacterial activity in which the single-walled CNTs were found to be much more toxic to bacteria than that of multiwalled CNTs $[29,30]$. Also, the longer SWCNTs indicated stronger antimicrobial activity due to their improved aggregation with bacterial cells $[31,32]$. Possible mechanism of antimicrobial activity of carbon nanotubes was proposed as follows: physical interaction with cell membrane; formation of cell-CNTs aggregates; induction of the cell membrane disruption [29]. Although the antibacterial activity of SWCNTs was superior to that of MWCNTs, the prices for synthesis of SWCNTs were high cost. Therefore, the economic advantages of MWCNTs are preferred than those of SWCNTs $[28,29]$.

Third, for the case of Ag-MWCNTs, the antibacterial activity of Ag-MWCNTs was attributed to synergistic effect of Ag-NPs and MWCNTs. The possible action mechanism of 


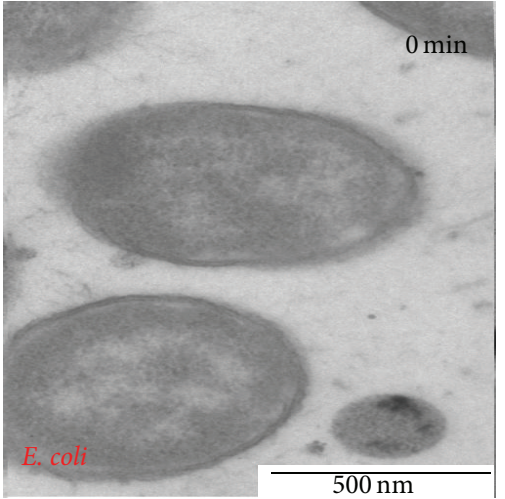

(a1)

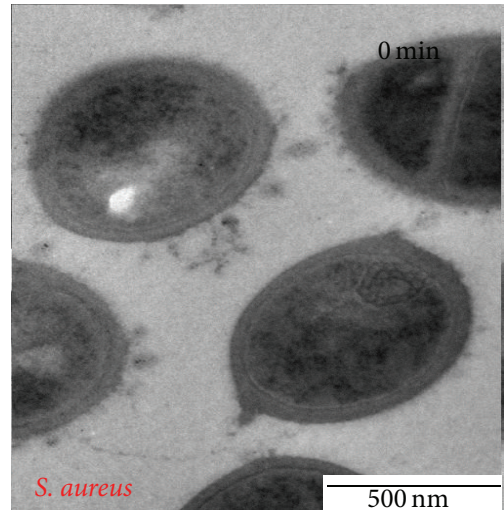

(b1)

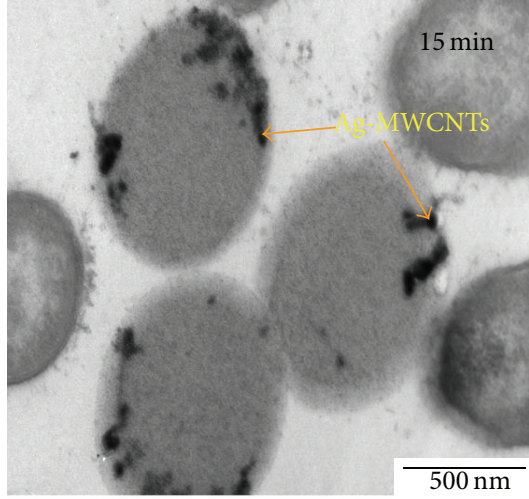

(a2)

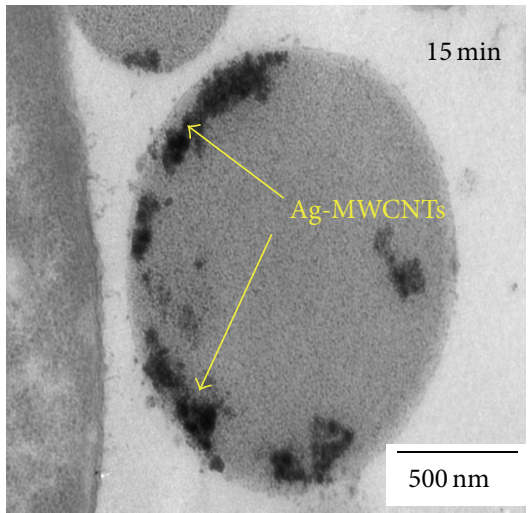

(b2)

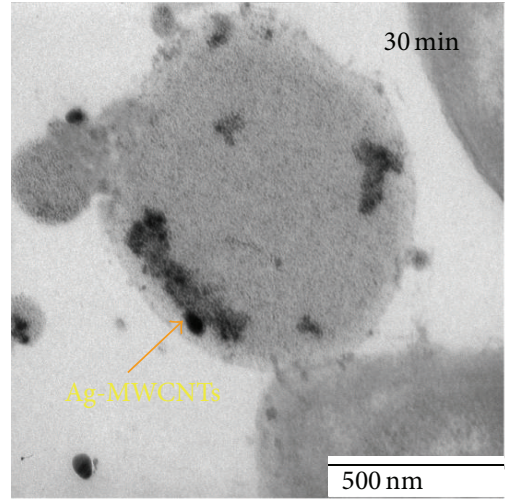

(a3)

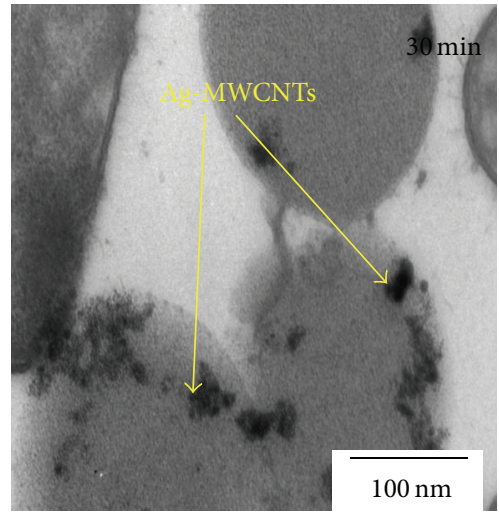

(b3)

FIGURE 6: The cross-sectional TEM images showing different stages of interaction of Ag-MWCNTs samples with E. coli and S. aureus bacteria cells after $0 \mathrm{~min}, 15 \mathrm{~min}$, and $30 \mathrm{~min}$.

bactericidal activity is likely to be the synergy of membrane stress and oxidative stress [32-34] in which the membrane stress mediated by direct physical contacts between AgMWCNTs with the cell membrane walls and oxidative stress caused by induction of reactive oxygen species (ROS) mediated by both the functionalized MWCNTs and Ag-NPs materials [27, 32]. The oxidative stress mediated by MWCNTs may come from $-\mathrm{OH}$ and $-\mathrm{COOH}$ groups functionalized on the surface, also resulting in production of the ROS [32]. The membrane stress is due to the large surface-to-volume ratio of silver nanoparticles and high-aspect ratio of MWCNTs [31]. The enhanced surface area of Ag-MWCNTs produced large contact between the bacterial cell membrane and material resulting in improvement of antibacterial efficiency [16]. Our ultrastructural analysis indicates that the cluster of Ag-MWCNTs nanocomposite can be easily interacted with the cell membrane of bacteria (yellow arrowhead). From observation in ultrastructural changes of bacterial cells (see Figure 6), the Ag-MWCNTs nanocomposite showed the large formation of cell-Ag-MWCNTs aggregates and faster destructibility of cell membrane and disruption of membrane function, hence resulting in cells death. The action of AgMWCNTs against E. coli and S. aureus bacterial cells was probed by ultrastructural analysis.

\section{Discussions}

In the present study, the mechanism for photochemical growth of Ag nanocrystals on the MWCNTs via Tollens reaction can be understood as follows [16-18]: after mixing silver ammonia complex (silver ions $\mathrm{Ag}^{+}$) with MWCNTs, the positively charged $\operatorname{Ag}\left[\left(\mathrm{NH}_{3}\right)_{2}\right]^{+}$can be easily attached to the negatively charged functional groups on the surface of acid-treated MWCNTs. The addition of glucose to the mixture results in the formation of silver nanoparticles, in which the aldehyde groups of glucose release electrons, and then silver ammonia complex was reduced into metallic $\mathrm{Ag}^{\circ}$ nanoparticles [18]. The high dispersions of Ag-NPs on the functionalized MWCNTs can be controlled by using UV irradiation during reduction process. The UV irradiation causes excitation of $\left[\mathrm{Ag}\left(\mathrm{NH}_{3}\right)_{2}\right]^{+}$ions followed by electron transfer from the glucose molecule to $\mathrm{Ag}^{+}$, thus producing $\mathrm{Ag}^{\circ}$ atoms which then form clusters and seeds $[17,18]$ :

$$
\begin{aligned}
& {\left[\mathrm{Ag}\left(\mathrm{NH}_{3}\right)_{2}\right]^{+}+\mathrm{RCHOH} \stackrel{h v}{\longrightarrow} \mathrm{Ag}^{\circ}+2 \mathrm{NH}_{3}+\mathrm{H}^{+}+\mathrm{RCOH}} \\
& n \mathrm{Ag}^{\circ} \longrightarrow\left(\mathrm{Ag}_{\mathrm{n}}\right)^{\circ}
\end{aligned}
$$

where $\mathrm{RCHOH}$ represents glucose in cyclic form. 
Our previous studies reported that, in Tollens reaction, the average diameter, particle size distribution, and aggregate stability of Ag nanocrystals were strongly dependent on the conditions of synthesis such as the temperature, ammonia concentration, and the change in the $\mathrm{pH}$ of the medium during the reduction process $[17,18]$. Furthermore, the addition of surfactants into the reaction medium could control the particle size and uniform aqueous dispersion of NPs. In our present case, the use of UV irradiation leads to the substantially simultaneous formation of a large amount of silver nuclei which then started to grow. This situation results in small dimensions $(\sim 7 \mathrm{~nm})$ and high dispersions of the finally obtained Ag-NPs on the functionalized MWCNTs. The remaining silver ions are adsorbed on the surface of already formed nanoparticles and attract oppositely charged oxygen functional groups on the MWCNTs through an electrostatic interaction to keep the reduced Ag nanocrystals staying on the surface of MWCNTs [21]. The strong interactions between Ag-NPs and the remaining hydroxyl and carboxyl groups on the surface of MWCNTs were confirmed from FTIR measurements. The photochemical method is a promising alternative for decoration of Ag nanocrystals on the carbon nanostructures (i.e., MWCNTs, graphene-based materials) for biomedicine and disinfection applications [16].

Based on ultrastructural analyses, it revealed that the antibacterial activity of Ag-MWCNTs was dependent on type of bacteria. The antibacterial efficacy of Ag-MWCNTs against E. coli bacteria is better than that of $S$. aureus bacteria, which is due to the difference in biological activity and thickness of cell wall of individual bacterial species. Our results reveal that the enhanced antibacterial activity of AgMWCNTs was attributed to synergistic effect of Ag-NPs and MWCNTs. In fact, the physical interactions between bacterial cells and Ag-MWCNTs play an important role in their antimicrobial mechanism. The presence of MWCNTs to increase the long-term stability of Ag-NPs should be noted. Furthermore, the superior surface area of MWCNTs initiated better interaction with the cell surface. Our ultrastructural observation provides deeper physical insights in interaction mechanism of Ag-MWCNTs nanocomposite and bacterial cells. The as-prepared Ag-MWCNTs nanocomposite showed a high potential for biomedicine and disinfection applications because of the interplay between the large surface area and strong adsorption property of the MWCNTs and high bactericidal and catalytic activities of the Ag-NPs.

\section{Conclusions}

In this study, we introduced a simple method for preparation of Ag-decorated MWCNTs nanocomposite using photochemical reaction. These prepared Ag-MWCNTs nanocomposites were found to display noticeable antibacterial activity against both Gram-negative and Gram-positive bacteria. Antibacterial action mechanism of Ag-MWCNTs with tested bacteria was probed by adapting the electron microscopy. Our ultrastructural studies confirmed that the antibacterial action of Ag-MWCNTs nanocomposite was synthetic effect from both Ag-NPs and MWCNTs. This method showed many advantages over other chemistry methods such as green synthesis, reaction occurring at room temperature, longterm stable aqueous dispersions, and small particles sizes. The small sizes and fine dispersions of Ag-NPs deposited on MWCNTs make it very promising for biomedicine and disinfection applications.

\section{Conflict of Interests}

The authors declare that there is no conflict of interests regarding the publication of this paper.

\section{Acknowledgments}

This work was supported by Vietnam's National Foundation for Science and Technology Development (NAFOSTED) through a fundamental research project (code: 103.042012.60). The technical supports for biological and TEM measurements at National Institute of Hygiene and Epidemiology (NIHE) are acknowledged.

\section{References}

[1] Global Report for Research on Infectious Diseases of Poverty, World Health Organization, 2012.

[2] M. Rai, Ed., Nano-Antimicrobials: Progress and Prospects, Springer, Berlin, Germany, 2012.

[3] M. Rai, A. Yadav, and A. Gade, "Silver nanoparticles as a new generation of antimicrobials," Biotechnology Advances, vol. 27, no. 1, pp. 76-83, 2009.

[4] X. Zhang, H. Niu, J. Yan, and Y. Cai, "Immobilizing silver nanoparticles onto the surface of magnetic silica composite to prepare magnetic disinfectant with enhanced stability and antibacterial activity," Colloids and Surfaces A: Physicochemical and Engineering Aspects, vol. 375, no. 1-3, pp. 186-192, 2011.

[5] S. Liu, T. H. Zeng, M. Hofmann et al., "Antibacterial activity of graphite, graphite oxide, graphene oxide, and reduced graphene oxide: membrane and oxidative stress," ACS Nano, vol. 5, no. 9, pp. 6971-6980, 2011.

[6] S.-J. Yu, Y.-G. Yin, and J.-F. Liu, "Silver nanoparticles in the environment," Environmental Sciences: Processes and Impacts, vol. 15, no. 1, pp. 78-92, 2013.

[7] S. Chernousova and M. Epple, "Silver as antibacterial agent: ion, nanoparticle, and metal," Angewandte Chemie-International Edition, vol. 52, no. 6, pp. 1636-1653, 2013.

[8] Q. H. Tran, V. Q. Nguyen, and A.-T. Le, "Silver nanoparticles: synthesis, properties, toxicology, applications and perspectives," Advances in Natural Sciences: Nanoscience and Nanotechnology, vol. 4, no. 3, Article ID 033001, 2013.

[9] R. Prucek, J. Tuček, M. Kilianová et al., “The targeted antibacterial and antifungal properties of magnetic nanocomposite of iron oxide and silver nanoparticles," Biomaterials, vol. 32, no. 21, pp. 4704-4713, 2011.

[10] W.-P. Xu, L.-C. Zhang, J.-P. Li et al., "Facile synthesis of silver@graphene oxide nanocomposites and their enhanced antibacterial properties," Journal of Materials Chemistry, vol. 21, no. 12, pp. 4593-4597, 2011.

[11] J. D. Kim, H. Yun, G. C. Kim, C. W. Lee, and H. C. Choi, "Antibacterial activity and reusability of CNT-Ag and GO-Ag 
nanocomposites," Applied Surface Science, vol. 283, pp. 227-233, 2013.

[12] W. Yuan, G. Jiang, J. Che et al., "Deposition of silver nanoparticles on multiwalled carbon nanotubes grafted with hyperbranched poly(amidoamine) and their antimicrobial effects," Journal of Physical Chemistry C, vol. 112, no. 48, pp. 18754-18759, 2008.

[13] A. B. Castle, E. Gracia-Espino, C. Nieto-Delgado, H. Terrones, M. Terrones, and S. Hussain, "Hydroxyl-functionalized and $\mathrm{N}$-doped multiwalled carbon nanotubes decorated with silver nanoparticles preserve cellular function," ACS Nano, vol. 5, no. 4, pp. 2458-2466, 2011.

[14] R. Mohan, A. M. Shanmugharaj, and R. Sung Hun, "An efficient growth of silver and copper nanoparticles on multiwalled carbon nanotube with enhanced antimicrobial activity," Journal of Biomedical Materials Research-Part B Applied Biomaterials, vol. 96, no. 1, pp. 119-126, 2011.

[15] Y. Seo, J. Hwang, J. Kim, Y. Jeong, M. P. Hwang, and J. Choi, "Antibacterial activity and cytotoxicity of multi-walled carbon nanotubes decorated with silver nanoparticles," International Journal of Nanomedicine, vol. 9, pp. 4621-4629, 2014.

[16] N. X. Dinh, D. T. Chi, and N. T. Lan, "Water-dispersible silver nanoparticles-decorated carbon nanomaterials: synthesis and enhanced antibacterial activity," Applied Physics A, 2015.

[17] A.-T. Le, P. T. Huy, P. D. Tam et al., "Green synthesis of finelydispersed highly bactericidal silver nanoparticles via modified Tollens technique," Current Applied Physics, vol. 10, no. 3, pp. 910-916, 2010.

[18] A.-T. Le, L. T. Tam, P. D. Tam et al., "Synthesis of oleic acidstabilized silver nanoparticles and analysis of their antibacterial activity," Materials Science and Engineering C, vol. 30, no. 6, pp. 910-916, 2010.

[19] N. T. Lan, D. T. Chi, N. X. Dinh et al., "Photochemical decoration of silver nanoparticles on graphene oxide nanosheets and their optical characterization," Journal of Alloys and Compounds, vol. 615, pp. 843-848, 2014.

[20] D. Tasis, N. Tagmatarchis, A. Bianco, and M. Prato, "Chemistry of carbon nanotubes," Chemical Reviews, vol. 106, no. 3, pp. 1105-1136, 2006.

[21] M. R. Das, R. K. Sarma, R. Saikia, V. S. Kale, M. V. Shelke, and P. Sengupta, "Synthesis of silver nanoparticles in an aqueous suspension of graphene oxide sheets and its antimicrobial activity," Colloids and Surfaces B: Biointerfaces, vol. 83, no. 1, pp. 16-22, 2011.

[22] M. R. Das, R. K. Sarma, S. C. Borah et al., "The synthesis of citrate-modified silver nanoparticles in an aqueous suspension of graphene oxide nanosheets and their antibacterial activity," Colloids and Surfaces B: Biointerfaces, vol. 105, pp. 128-136, 2013.

[23] B. Wu, Y. Kuang, X. Zhang, and J. Chen, "Noble metal nanoparticles/carbon nanotubes nanohybrids: synthesis and applications," Nano Today, vol. 6, no. 1, pp. 75-90, 2011.

[24] A.-T. Le, P. T. Huy, L. T. Tam, P. D. Tam, N. V. Hieu, and T. Q. Huy, "Novel silver nanoparticles: synthesis, properties and applications," International Journal of Nanotechnology, vol. 8, no. 3-5, pp. 278-290, 2011.

[25] M. Sakamoto, M. Fujistuka, and T. Majima, "Light as a construction tool of metal nanoparticles: synthesis and mechanism," Journal of Photochemistry and Photobiology C: Photochemistry Reviews, vol. 10, no. 1, pp. 33-56, 2009.

[26] M. J. Hajipour, K. M. Fromm, A. Akbar Ashkarran et al., "Antibacterial properties of nanoparticles," Trends in Biotechnology, vol. 30, no. 10, pp. 499-511, 2012.
[27] C. Marambio-Jones and E. M. V. Hoek, "A review of the antibacterial effects of silver nanomaterials and potential implications for human health and the environment," Journal of Nanoparticle Research, vol. 12, no. 5, pp. 1531-1551, 2010.

[28] S. M. Dizaj, A. Mennati, S. Jafari, K. Khezri, and K. Adibkia, "Antimicrobial activity of carbon-based nanoparticles," Advanced Pharmaceutical Bulletin, vol. 5, no. 1, pp. 19-23, 2015.

[29] S. Liu, A. K. Ng, R. Xu et al., "Antibacterial action of dispersed single-walled carbon nanotubes on Escherichia coli and Bacillus subtilis investigated by atomic force microscopy," Nanoscale, vol. 2, no. 12, pp. 2744-2750, 2010.

[30] O. Akhavan and E. Ghaderi, "Toxicity of graphene and graphene oxide nanowalls against bacteria," ACS Nano, vol. 4, no. 10, pp. 5731-5736, 2010.

[31] C. Yang, J. Mamouni, Y. Tang, and L. Yang, "Antimicrobial activity of single-walled carbon nanotubes: length effect," Langmuir, vol. 26, no. 20, pp. 16013-16019, 2010.

[32] A. A. Shvedova, A. Pietroiusti, B. Fadeel, and V. E. Kagan, "Mechanisms of carbon nanotube-induced toxicity: focus on oxidative stress," Toxicology and Applied Pharmacology, vol. 261, no. 2, pp. 121-133, 2012.

[33] S. Kang, M. Herzberg, D. F. Rodrigues, and M. Elimelech, "Antibacterial effects of carbon nanotubes: size does matter!" Langmuir, vol. 24, no. 13, pp. 6409-6413, 2008.

[34] C. D. Vecitis, K. R. Zodrow, S. Kang, and M. Elimelech, "Electronic-structure-dependent bacterial cytotoxicity of single-walled carbon nanotubes," ACS Nano, vol. 4, no. 9, pp. 5471-5479, 2010. 

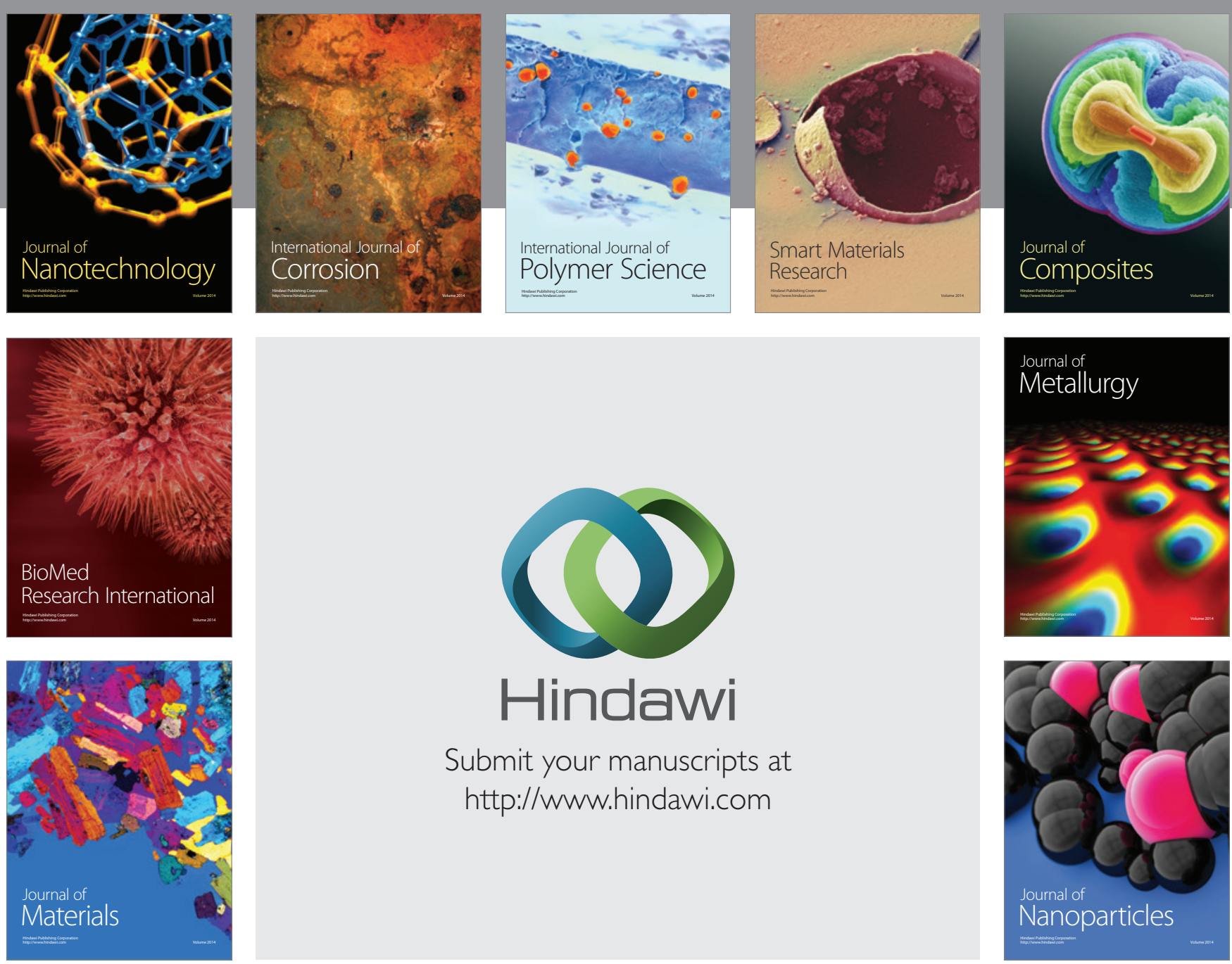

Submit your manuscripts at http://www.hindawi.com
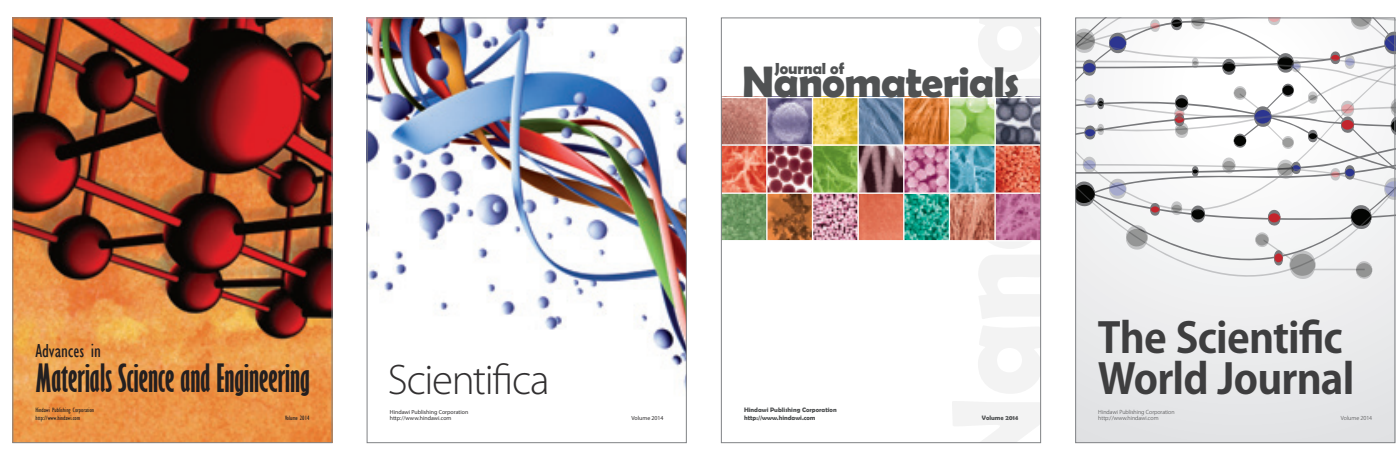

\section{The Scientific World Journal}
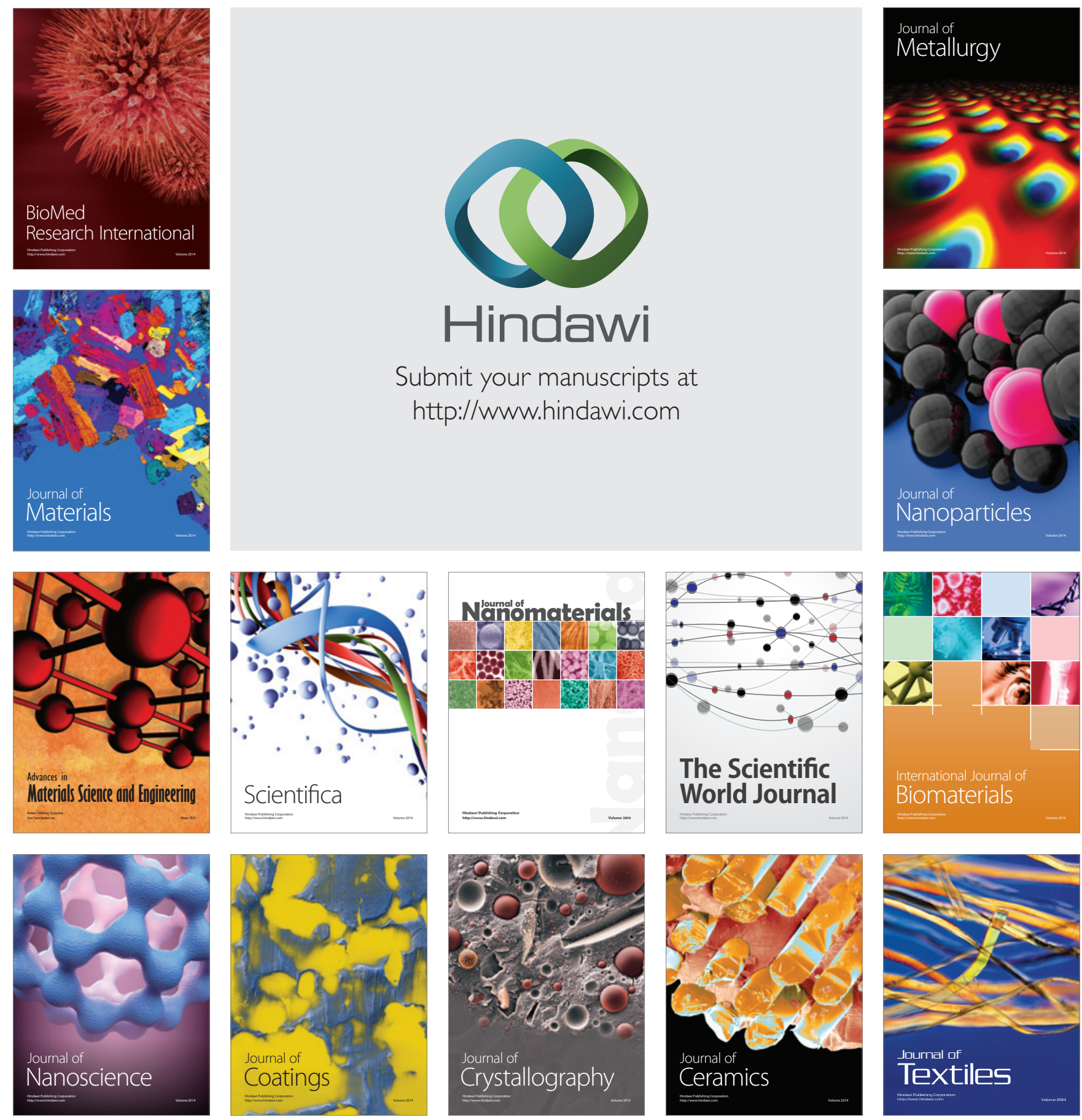